\title{
ALTERNATIVE FILTRATION TESTING PROGRAM: PRE-EVALUATION OF TEST RESULTS (U)
}

by'

G. K. Georgeton and M. R. Poirier

Westinghouse Savannah River Company

Savannah River Site

Aiken, South Carolina 29808

A report to be sent to OSTI and for general public distribution

This reportwas prepared in connection with work done under Contract No. DE-AC09-89SR18035 with the U.S. Department of Energy. By acceptance of this report, the publisher and/or recipient acknowledges the U.S. Government's right to retain a nonexclusive, royalty-free license in and to any copyright covering this report along with the right to reproduce and to authorize others to reproduce all or part of the copyrighted report

\section{DISCLAIMER}

This report was prepared as an account of work sponsored by an agency of the United States Government. Neither the United States Government nor any agency thereof, nor any of their employees, makes any warranty, express or implied, or assumes any legal liability or responsibilit; for the accuracy, completeness, or usefulness of any information, apparatus, product, or process disclosed, or represents that its use would not infringe privately owned rights. Reference herein to any specific commercial product, process, or service by trade name, trademark, manufacturer, or otherwise does not necessarily constitute or imply its endorsement, recommendation, or favoring by the United States Government or any agency thereof. The views and opinions of authors expressed herein do not necessarily state or reflect those of the United States Government or any agency thereof. 
WESTINGHOUSE SAVANNAH RIVER CO. SAVANNAH RIVER LABORATORY

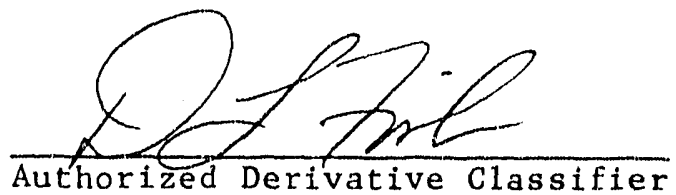

WSRC-RP-90-1145

KEYWORDS:

Alternative filters, Norton ceramic

filter, centrifugal.

ultrafilter, tubular

ultrafilter, pilot

testing arid

evaluatior

Retention time:

Permanent

September 28, 1990

TO: D. In Fish, $773-A C$

FROM: G. Ks. Georgeton, $773-A$ and M. R. Poirier, 676-T

\section{Alternative Filtration Testing Program: Rreliminary Evaluation of Filter Test Results}

\section{SUMMARY}

Based on results of testing eight solids removal technologies and one pretreatment option, it is recommended that a centrifugal ultrafilter and a polymeric ultrafilter undergo further testing as possible alternatives to the Norton ceramic filters. Deep bed filtration should be considered as a third alternative, if a backwashable cartridge filter is shown to be inefficient in separate testing.

\section{INTRODUCTION}

A research program was undertaken to identify and evaluate different filtration technologies as potential replacements for the Norton ceramic filters currently in use at the F/H Effluent Treatment Facility (ETF). The purpose of the experimental program was to collect data on each unit's efficiency based on quality and net quantity of filtrate. Similar data from all the units would then be evaluated and compared by SRS personnel. to select the 2 or 3 most pronising alternatives for further in-plant testing.

Several technologies were examined for their ability to effectively remove inorganic solids of the type, size and guantity found in the Norton influent. Bot» dead end filtration (i.e. all the liquid passes through the filter medium) and crissflow 
filtration (i.e. some of the liquid is used to sweep solids off of the filter surface) were considered. The main criterion in determining applicability was the projected ability of an option to produce filtrate with turbidity below 1 NTU and silt density index (SDI) below 3 . Other points considered were simplicity of operation, anticipated fouling and requisite cleaning, and minimal waste production. Nine alternatives were identified for testing eight filters and one pretreatment option.

Pilot-scale filter units were leased from suppliers and were tested using a standard wastewater simulant. Analytical.

Entexprises, Inc. (AEI) in Columbia, SC was contracted to make all arrangements and to perform testing of soven of the filters and a Norton ceramic filter as a control. The remaining filter unit and pretreatment option were tested by the equipment's vendors.

This report summarizes initial results of the Alternative Filtration Program, and encompasses work completed between $7 / 1 / 90$ and $9 / 27 / 90$. Based on this information, 3 options are recommended for further testing using actual ETE wastewater. More detailed description of each option, including comparison to the control case, final chemical analyses of collected samples, and advantages and disadvantages of each technology, will be presented as separate documents.

\section{EXPERIMENTAL}

The various alternatives evaluated during this project are listed in Table I. Suppliers of each option and the cognizant representative are listed in Appendix A.

Each unit was challenged with a standard simulant prepared according to the specification in Table II. This recipe produced a solution that contained approximately 40 - $50 \mathrm{ppm}$ suspended solids, including hard-to-filter colloidal material. Turbidity of the simulant prepared for the experiments ranged from 9-12 NTU when adequate agitation was maintained.

Each unit was operated in single pass mode (i.e. filtrate and concentrate discarded rather than reforming feed), with the exception of the centrifugal ultrafilter. The spintek system was fed from a vessel having approximately a 30-minute turnover time. The units were operated for at least 10 continuous hours. In some units, continuous operation was occasionaliy interrupted for 5-10 minutes when backwashing/cleaning was necessary.

The test units were set up and operated by the representatives of the respective suppliers, and all testing was witnessed by SRS personnel. The centrifugal ultrafilter and the electrocoagulator were tested by the equipment vendors, and the remaining units were tested by AEI. Samples were collected for analyses of turbidity, SDI, total suspended solids, and $F e, A I$ and $S i$ concentrations. In the testing performed by AEI, all analyses were performed by AEI 
personnel. In the tests performed by the individual vendors, samples were sent to registered laboratories for analysis.

In some instances, testing was aborted prematurely when it was clear that a filter unit could not satisfy the specified quality requirements. The testing of the electrocoagulator was separated into preliminary testing to determine the most optimal conditions, followed by continuous testing. Evaluation of this unit was aborted before the ten hour test because preliminary results did not indicate any appreciable effect on the simulated wastewater.

\section{DISCUSSION}

Of the options tested, several produced filtrate that satisfied the 1 NTU limit. The two technologies showing the most promise were both based on membrane technology, the centrifugal

ultrafilter (CUF) and the tubular ultrafilter (TUF). The deep bed filter also produced filtrate with the desired quality. The backpulsable polymeric cartridge showed some promise but needed more testing to establish credibility. The tubular fabric and centrifuge were rejected because they did not satisfy the filtrate turbidity limit, and the stainless steel mesh and porous metal filters were rejected because of fouling tendencies similar to those of the Norton filter. The electrocoagulation pretreatment option was rejected because no significant beneficial effects on the particles were observed.

Table I. Filters Tested During Alternative Filtration Program Technology Manufacturex

Centrifugal Ultrafilter (Spintek)

Deep Bed Filtration

Stainless Steel Mesh

Sintered Stainless Steel Powder

Backwashable Polymeric Cartxidge

Polymeric Ultrafilter Membrane

Tubular Eabric

Electrocoagulation pretreatment

Centrifuge

Norton Ceramic for baseline
AquaTechnology

Culligan water Treatment

FUJI America, Inc.

Pall Corporation

Pall Corporation

$\mathrm{KOCH}$ Membrane

Systems, Inc.

Ronningen-Petter

Duratek Corp.

A.la-Laval Co.

Milipore 


\section{Ceramic Filter}

A Millipore (Norton Filter) test unit was evaluated to establish a baseline for comparison of utility of the various filter alternatives. The test unit contained six elements of the same type currently in use at the ETE. Feed was introduced at approximately $6 \mathrm{gpm}$, and was combined with an internal recycle stream to produce flow with a crossflow velocity of approximately $17 \mathrm{ft} / \mathrm{sec}(23 \mathrm{gpm})$. The trans membrane pressure (TMP) was adjusted to approximately $30 \mathrm{psi}$. The unit was backflushed with clean water for 3 minutes after every 30 minutes of operation. The feed pump was turned off during the backwash procedure, except for "bumping" once or twice to remove extra solids in the lines. The line pressure of the backwash water was 80 psi. Filter performance agreed well with simulant testing performed at TNX. Permeate turbidity was consistently well below $0.5 \mathrm{NT} U$, but as seen in Figure 1, permeate flux decreased due to solids fouling the ceramic. The normalized permeate flux for the average of each filter/clean cycle is also shown in Figure 1 . The test unit. afforded a high crossflow velocity and ideal backpulsing, yet the fouling tendency is still reflected by a $25 \%$ loss in permeate rate over the 5-hour period.

Table II. Composition of ETE Simulant

\section{Compound}

$\mathrm{NaNO}_{3}$

$\mathrm{NaHCO}_{3}$

$\mathrm{NH}_{4} \mathrm{NO}_{3}$

$\mathrm{Na}_{2} \mathrm{SiO}_{3} \cdot 9 \mathrm{H}_{2} \mathrm{O}$

$\mathrm{Al}\left(\mathrm{NO}_{3}\right)_{3} \cdot 9 \mathrm{H}_{2} \mathrm{O}$

$\mathrm{Fe}\left(\mathrm{NO}_{3}\right)_{3} \cdot 9 \mathrm{H}_{2} \mathrm{O}$

$\mathrm{CaCO}_{3}$

$\mathrm{Na}_{2} \mathrm{SO}_{4}$

$\mathrm{NaNO}_{2}$

$\mathrm{NaCl}$

$\mathrm{MgSO}_{4} \cdot 9 \mathrm{H}_{2} \mathrm{O}$

$\mathrm{NaF}$

$\mathrm{MnCl}_{2} \cdot 4 \mathrm{H}_{2} \mathrm{O}$

$\mathrm{Zn}\left(\mathrm{NO}_{3}\right)_{2}$

$\mathrm{Ba}\left(\mathrm{NO}_{3}\right)_{2}$

Tri n-butyl phosphate (TBP) concentration $(\mathrm{gm} / 1)$

1.257

0.10

0.0836

0.0675

0.0378

0.0414

0.0107

0.0074

0.0023

0.0017

0.0044

0.0011

0.0011

0.0009

0.00004

0.050 


\section{Centrifugal Ultrafilter}

The centrifugal ultrafiltration unit contained $9.6 \mathrm{ft}^{2}$ of 100,000 nominal molecular weight cutoff (NMWC) PVDF membrane, arranged as three flat sheet discs. (A more detailed description of the unit and the testing of the unit can be found in the Reference.) Feec. was introduced into the housing at $3 \mathrm{gpm}$ and $50 \mathrm{psi}$. The discs were rotated at $1000 \mathrm{rpm}$, effectively creating a very high crossflow velocity. Additionally, the centrifugal force caused the solid particles to be sloughed off. The typical polarization layer did not form on the membrane surface, and this was apparent as the permeate flux remained around $140 \mathrm{gfd}$. Turbidity of the permeate was consistently measured to be below 0.6 NTU. There was no cleaning required during the 10 hours. Solids that did accumulate on the outer fringes of the membranes were later dislodged by simply stopping and restarting the rotation of the unit.

The centrifugal ultrafilter was demonistrated to have the most consistent flux rate and utility. The normalized permeate flux is compared to the average normalized flus (for each cycle) for the Norton filter test unit in Figure 2. The permeate flux through the CUF remained around $140 \mathrm{gfd}$ for the entire 10 hours, as compared to the 25\% recline observed through the ceramic filter in 5 hours. (Most of the variation in the operational data for the CUF was attributed to experimental errox.) In addition, the CUF continued steady operation, and did not have to be taken off line for cleaning, as did the ceramic filter unit. Because of the steady flux rate and excellent utility over the ten hour period, the CUF was considered to be a possible technology for replacing the Norton filters.

\section{Tubular Ultrafilter}

The tubular ultrafilter consisted of 1-inch diameter elements of a negatively charged PVDF membrane having a 50,000-100,000 NMWC. The membrane tubes provided $17.6 \mathrm{ft}^{2}$ of surface area. The unit was operated in a feed and bleed arrangement, at approximately a $5 \mathrm{gpm}$ feed rate. Flow through the tubes was about $30 \mathrm{gpm}$, resulting in a crossflow velocity of $15 \mathrm{ft} / \mathrm{sec}$. The TMP was set at $27.5 \mathrm{psi}$, which resulted in an initial permeate flux of $180 \mathrm{gfd}$. The membrane exhibited the normal flux decline associated with the buildup of a polarization layer, but the decline was more gradual than observed in the cyclic operation of the ceramic microfilters. After 5 hours of operation, the initial flux was restored by forcing sponge balls down the length of the elements to remove the polarization layer on the membrane surface. At all times, filtrate turbidity was less than 0.3 NTU, which is well below the 1-NTU limit. The TUF test unit was operated continuously, even during cleaning with the sponge balls.

The change in permeate flux of the TUF was comparable to that of the ceramic filter, as seen in Figure 2. Nelther the TUF nor the Millipore fllter reached a steady flux level during the period of operation compared here. However, the utility of the TUF was better 
overall because the system was kept online for 5 consecutive hours before being cleaned. In addition, physical cleaning was sufficient: to restore the initial flux to the membrane; whereas, chemical cleaning was necessary for the ceramic filter. Although the membrane permeate flux may mimic that of the ceramic filter, the cleaning and overall utility suggest that the tubular ultrafilter may be a viable alternative.

\section{Deep Bed Filter}

The deep bed filtration test unit consisted of a clarifier, followed by a mixed media bed. Because of the mostly colloidal material in the simulant, the clarifier contributed minimally to the filtration. The media in the second bed were various grades of sand and a layer of anthracite supported by a relatively coarse gravel. The simulant was fed to the unit at $13 \mathrm{gpm}\left(6 \mathrm{gpm} / \mathrm{ft}^{2}\right)$ and $70 \mathrm{psi}$ without any flocculating agents to coagulate the particles. Filtrate turbidity remained below 1 NTU for about 1 hour. The beds were then backwashed using fresh water at 3 times the forward rate for 25 minutes. The bed was then used to filter simulant that contained 2-3 ppm of a proprietary polymeric flocculant. Filtration continued for 4 hours before the filtrate turbidity exceeded 1 NTU. The beds were backwashed as before, and flow was restarted using a polymer/alum mixture as a flocculant. The supplier of the deep beds experimented with various levels of the coagulants to try to optimize the addition. After 3 hours, the beds were backwashed again to complete the testing.

The deep bed filter can effectively produce filtrate with turbidity less than 1 NTU. This requires addition of a polymeric coagulant to pretreat the solids. The major drawback of this technology is the amount of water necessary to clean the media. During this test, a volume equivalent to $56 \%$ of the total amount of water filtered was used to backwash the beds. Assuming that the backwash was twice what was necessary (i.e. overkill just for the test), the net would be $72 \%$ of every 100 galions filtered. Howevex, the simplicity of and experience with this type of fllter make the deep bed a possible alternalive on which to fall back if other technologies are proven ineffective.

\section{Backwashable Cartridge Filter}

The polymeric backwashable cartridge filter tested was a 10-inch element with a $1 \mu$ absolute rating. The simulant was filtered in a dead end arrangement at a constant flow rate of $0.25 \mathrm{gpm}$ (rate recommended by the supplier) and $40 \mathrm{psi}$. The time to achieve a differential pressure (DP) of 15 psi across the filter was over 60 minutes on the first cycle. The element was then backpulsed with 40-psi. air to remove solids trapped in the filter medium. The backpulse sequence consisted of several rapid pulses in succession. This was followed by a complete backward flush. The next filtration cycle took approximately 11 . minutes to reach the DP limit, indicating that many of the solids were still trapped in tre filter. Increasing the backpulse pressure to 60 psi resulted in the next 
cycle lasting 15 minutes. This implied that more solids were removed by the stronger pulse. The filtration time in each cycle decreased to 11 minutes over the next 6 cycles. The next cycle time increased to 37 minutes after soaking the cartridge in water overnight. The time to reach the DP limit decreased to 14 minutes through the next 9 cycles. The test was prematurely ended when the element split during backpulsing on the 20 th cycle. The turbidity of the filtrate rellained below 1 NTU except during the first few minutes of the firs: $4-5$ cycles.

The experimental work indicated that the backwashable cartridge filter could produce filtrate with turbidity less than 1 NTU. However, a consistently reproducible cycle time was not achieved. A steady value of cycle time would have to be established in order to determine the utility of the filter. Preliminary tests by the supplier on a smaller test unit using D-Tank watër (simulant originally used during cold testing of the ETF Norton filters) initially showed excellent reproducibility.

The significance of the element failure during testing is not completely known. The vendor representative indicated that the cartridge tested did not have the rigid support that is available for vigocous backpulsing applications. Thus the test results were inconclusive. The simplicity of this technology would suggest that separate testing should be considered to answer the remaining questions.

\section{Porous Metal Filter.}

The porous metal filter (10-inch sintered stainless steel powder cartridge) used in the test had a $5 \mu$ absolute rating. This element was tested in the same configuration as the backwashable cartridge filter. The filtrate turbidity remained above 1 NTU for the first 2 minutes of operation during the first 5 cycles. The turbidity fell below 0.5 NTU once enough solids accumulated on the surface or in the pores. The time to reach a 15-psi DP was about 18 minutes for the first cycle. The filter was backpulsed with 40-psi air when the DP limit was achieved. The backpulse operation consisted of two backward flushes immediately followed by several rapid air pulses in succession. The filtration time dropped by approximately one half after 27 filter/clean cycles due to solids not being completely removed from the pores on each cycle. Although the filtrate quality was satisfactory, the test was stopped because of the $50 \%$ loss in utility within 6 hours of filtration time. The element would require chemical cleanings to restore throughput on a similar frequency to that used on the Norton filter. Therefore, the porous metal element was rejected as a possible alternative.

\section{Stainless Steel Mesh Filter}

The stainless steel mesh filter ( $2 \mu$ rating) was aralogous to the porous metal filter, but with a higher pressure rating. The 20 -inch element was backpulsed vigorously with 250 psi steam. The unit initially filtered simulant at 7-8 $\mathrm{gpm}$ in dead end operation. The 
system's 45 psi DP was reached within $3-4$ minutes. The repeatability of filtration times following backpulsing was not demonstrated. This indicatod that even the high pressure backpulse was not able to completely remove the sticky solids from the filter. The cycle times were neither productive nor consistent even at low flow rates ( $1 \mathrm{gpm})$. The turbidity of filtrate samples collected during several. cycles was well above the 1-NTU limit. The test was aborted and the filter rejected because of the quick loading and subsequent fouling and poor filtrate quality. The results from testing of sieel elements indicate a similarity with the ceramic medium. It appears that an electrostatic attraction exists between particies and the filter in both cases.

\section{Tubular Fabric Filter}

The tubular fabric filter was rejected because filtrate turbidity was well above the 1 NTU limit. It was expected that the $1-3 \mu$ rated fabric would trap enough particles to form a thin depth layer that would act to filter particles smaller than $1 \mu$. This unit was operated in dead end fashion and backwashed when the DP reached 25 psi. Surprisingly, the DP limit was initially reached within 5-10 minutes. Filtration times for successive cycles were even shorter. The unit was subjected to feed flows between 0.75 and $10 \mathrm{gpm}$ and the best filtrate turbidity achieved was $4.5 \mathrm{NTU}$.

Inspection of the element revealed a brown color that indicated that particles were trapped in and on the fauric. Backwashing with water at $40-50 \mathrm{gpm}$ at $50 \mathrm{psi}$ did not remove the solids. Soaking the element in $1 \mathrm{M}$ nitric acid for 1 hour removed a large quantity of solids and increased the filtration time of the next cycle. The time to reach the DP limit decreased in succeeding cycles, and eventually the test was aborted.

\section{Centrifuge}

The centrifuge was also rejected due to it's poor quality product. Feed was initially introduced to the unit at $2 \mathrm{gpm}$. Collected solids were discharged every 25 minutes. Spinning at $8250 \mathrm{rpm}$, the unit produced overflow with turbidity of 7 NTU. An attempt was made to optimize conditions in the centrifuge by reducing the feed rate to $0.5 \mathrm{gpm}$ and by increasing the discharge frequency to. $15 / \mathrm{hr}$. The low flow provided a long residence time, and the frequent discharge prevented a large solids accumulation and cross contaminaliun. The lowest value of filtrate turbidity achleved was 3.4 NTU. This is well above the 1 -NTU requirement. It is apparent that practical use of the centrifuge is primarily limited to removal of large particles.

\section{Electrocoagulator}

The electrocoagulator electrolytically dissolved aluminum and/or iron electrodes into the solution. Ideally, the extra metals would act to flocculate the colloidal material and significantly reduce the number of particle smaller than $0.2 \mu$. The resulting particles would be also be more crystalline and more easily filtered. 
Preliminary tests of the electrocoagulation unit indicated that there was only minimal effect on the particle size distribution of the solids. Simulant was passed through three electrode arrangements at four different voltages. In all cases, there was little change in the particle size distribution. Thus, little or no change in the filtration characteristics would be expected. Apparently, more solids than are normally present in ETF wastewater are required for this technology to be effective. Consequently, the electrocoagulation unit was rejected as a possible option.

\section{CONCLUSIONS}

The centrifugal ultrafilter and the tubular ultrafilter were determined to be the most efficient of the eight filtration technologies and one pretreatment option tested. Deep bed filtration was also found to be capable of producing the desired filtrate quality, but it has drawbacks relating to utility. The results from testing the backwashable cartridge filter were inconclusive. The stainless steel mesh, porous metal and tubular fabric filters, centrifuge, and electrocoagulation pretreatment were shown to be inefficient as alternatives.

It is recommended that the centrifugal ultrafilter and the tubular ultrafilter be considered for further in-plant testing. Although there are drawbacks, a deep bed filter should currently be considered as a third alternative, in case membrane technologies are later found to be ineffective. Finally, separate testing should be conducted to establish the credibility of the backwashable cartridge filter as a third alternative.

\section{QUALITY ASSURANCE}

All work in this study was performed in concurrence with the SRS QA manual. Filter units were operated by the supplier's representative, following standard procedures for the equipment. Experimental data and samples were collected by the testing vendor's representative, and all operations were supervised by SRL personnel. Sample analysis was performed by AEI personnel in accordance with their standard procedures as an EPA-approved laboratory using standards traceable to NIST. All experimental data will be submitted with the record copies of the reports documenting testing of the individual options.

\section{REFERENCE}

Georgeton, G. K., IWT-LWP-90-0010, Memorandum to D. L. Fish, May 2, 1990. 
CC: W. L. Tamosaitis, 773-A

I. K. Sullivan, 703-H

S. T. Wach, 703-H

A. W. Wiggins, ETF

D. F. Brown, 703-H

R. R. Kulkarni, ETF

C. B. Sherburne, ETF

P. M. Stapf, ETF

D. J. McCabe, 676-T

L. L. Kilpatrick, 676-T

J. L. Siler, 676-T

J. P. Bibler, 773-A

SRL Records 
D. L. Fish - 11- WSRC-RP-90-1145

Appendix A.

Technology

Centrifugal Ultrafilter

Deep Bed Filtration

Stainless Steel Mesh

Sintered Stainless Steel. Powder

Backwashable Polymeric Cartridge $\checkmark$

Polymeric Ultrafilter Membrane

Tubular Fabric

Electrocoagulation pretreatment

Centrifuge

Norton Ceramic for baseline

\section{Sentact}

William Greene AquaTechnology (213) 376-3241

Henry G. Daniels Culligan Water ireatment (803) 356-4014

Seth J. Perkinson The Perkinson Co. (704) 525-8191.

Lawrence $D$. Weber Pall Corporation (516) 671-4000

Lawrence $D$. Weber Pall Corporation (516) 671-4000

Norman Jardine Equipment Associates, Inc. (704) 522-0170

Randy McKnight Mec-Tric Control Co. (704) 376-8555

Chester Fisher Duratek Corp. (301) 290-2340

Al Goble Separation Equipment Co. (813) 685-2065

Burke Fahlman Millipore

(800) 225-3384 


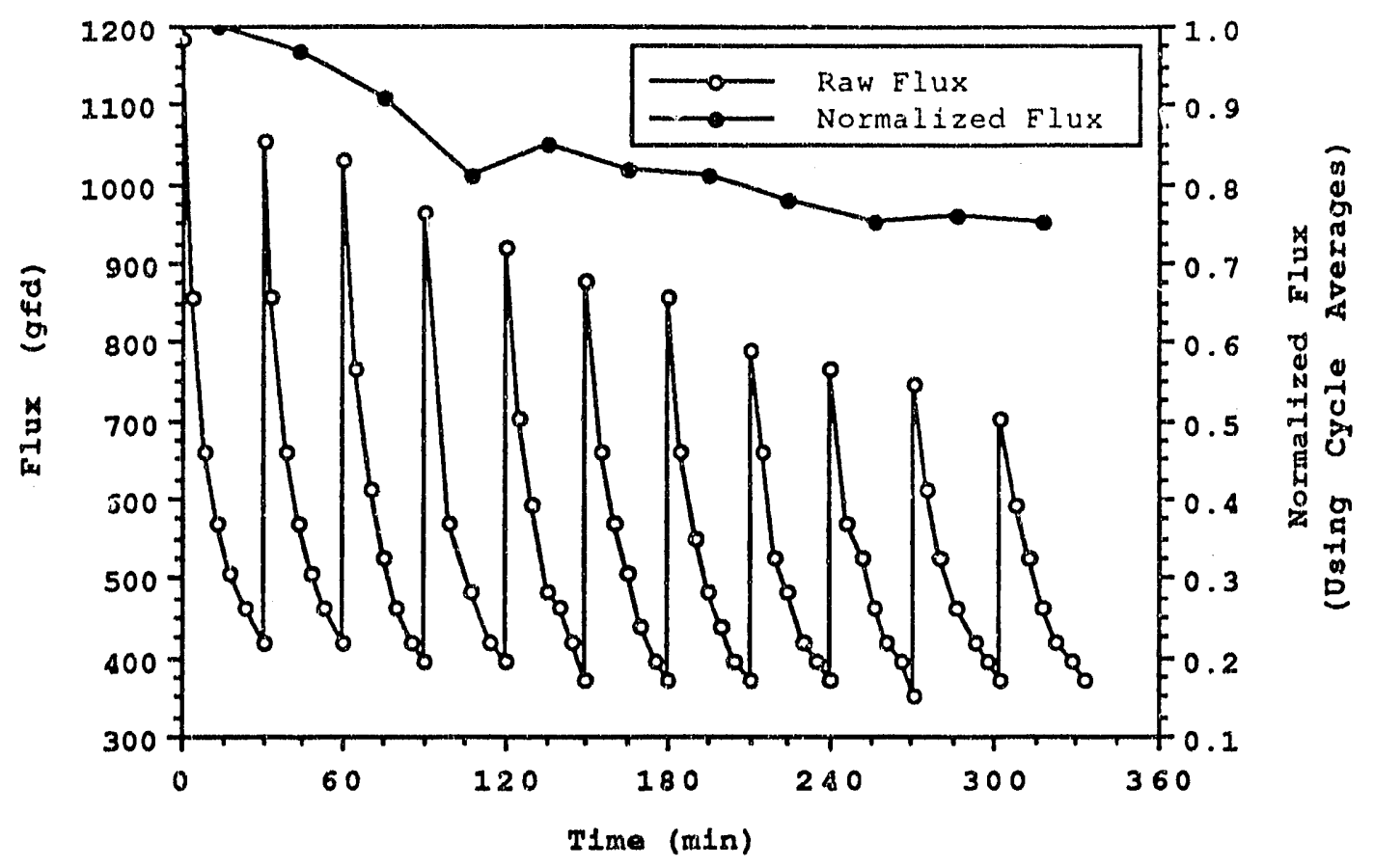

Figure 1. Millipore Ceramic Filter Baseline Determination

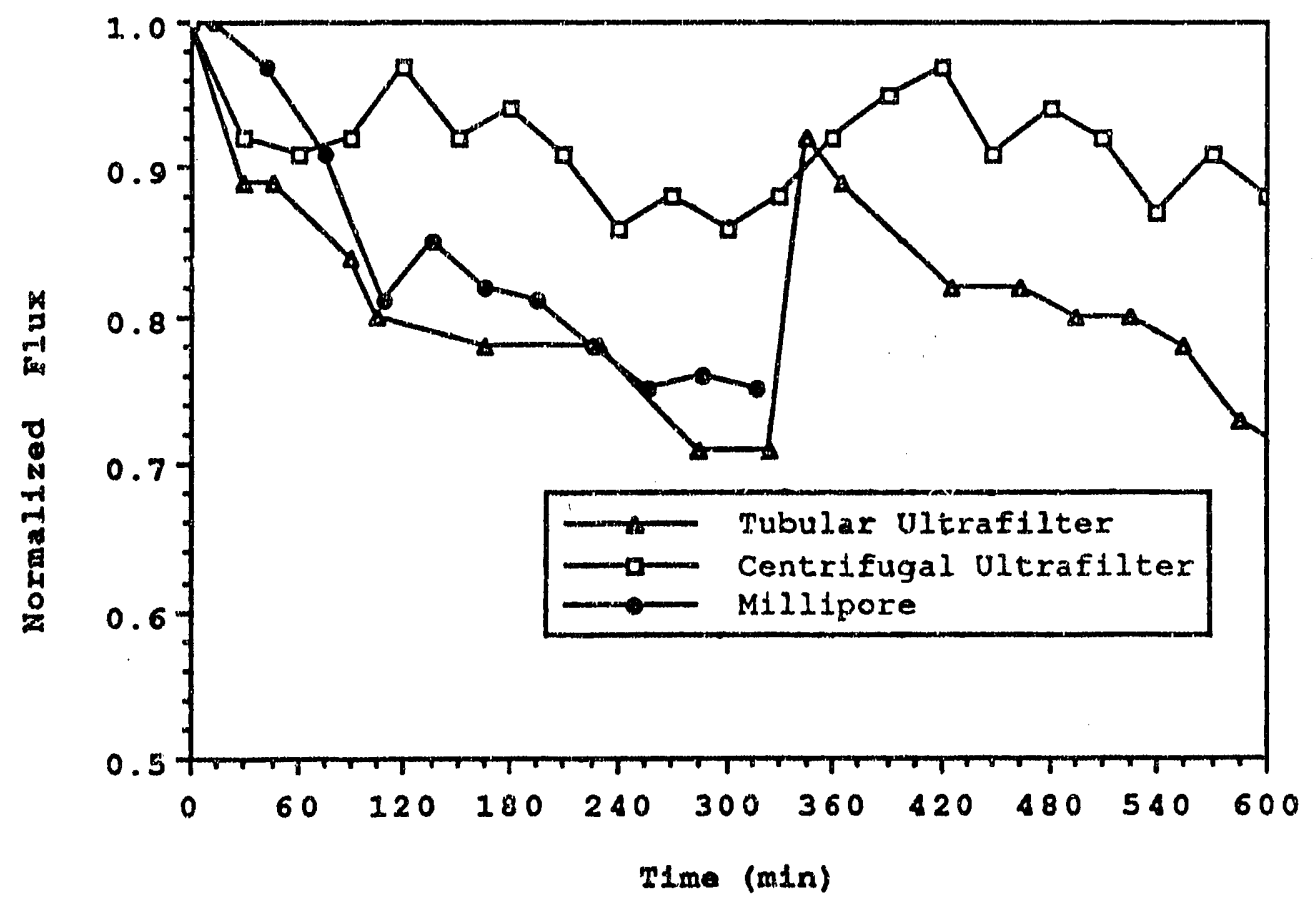

Figure 2. Comparison of UF and Millipore Performance 

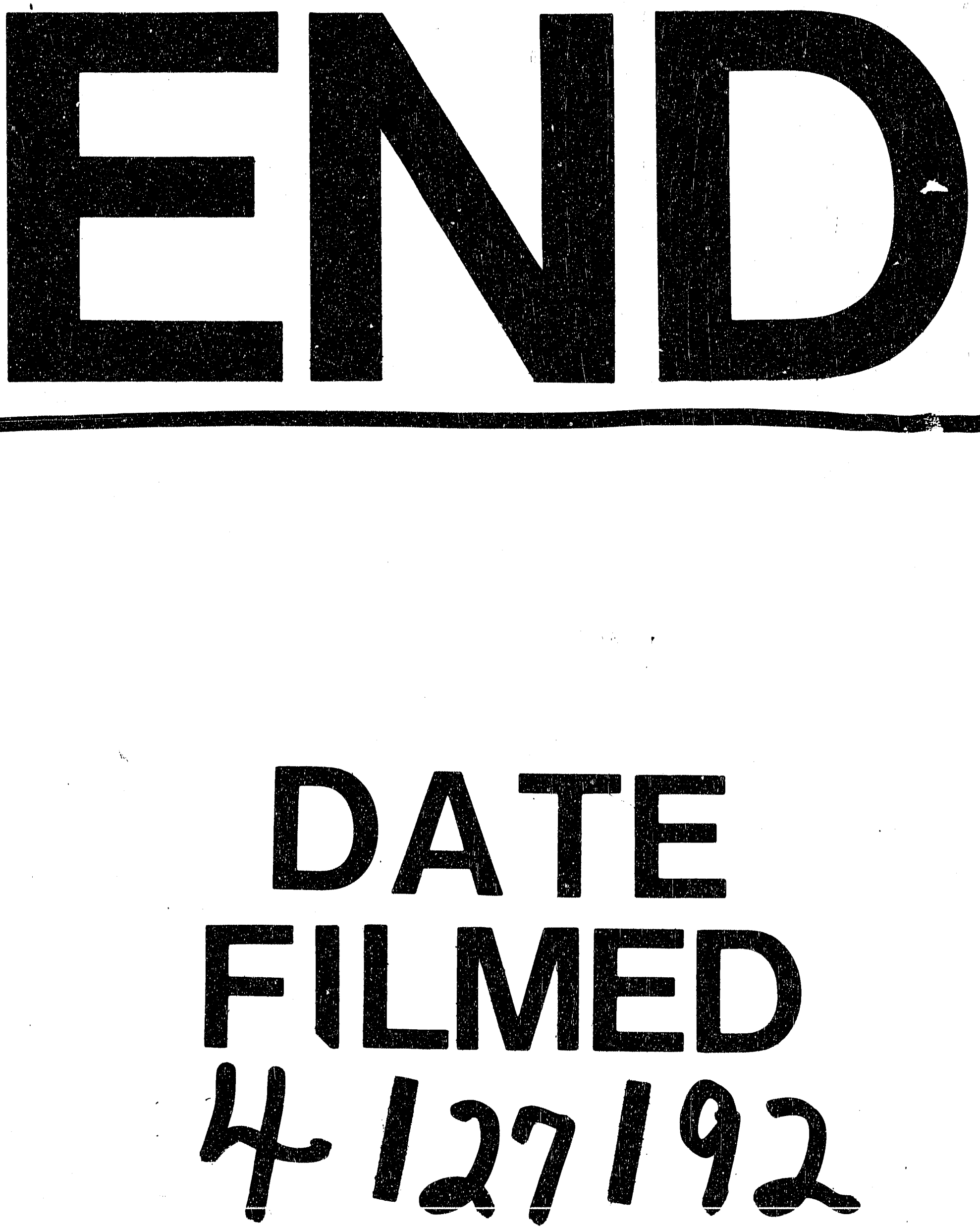


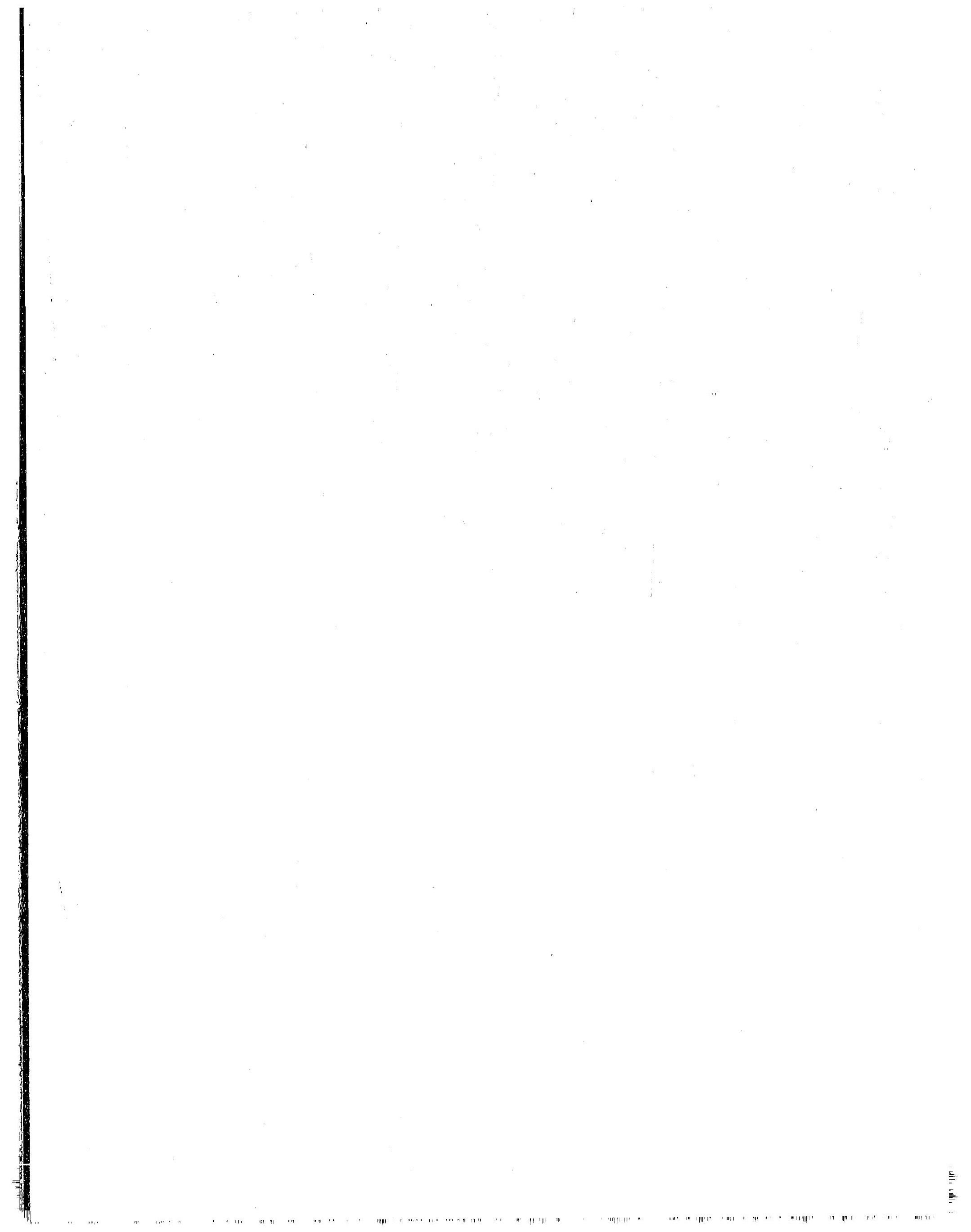

